\title{
PERAN KEPUASAN PELANGGAN DALAM MEMEDIASI PENGARUH INOVASI PRODUK TERHADAP LOYALITAS PELANGGAN (Studi pada Konsumen Warunk Upnormal)
}

\author{
Dinda Sukma Rangga Wati ${ }^{1}$ \\ I.G.A.K Sri Ardani \\ ${ }^{1,2}$ Fakultas Ekonomi dan Bisnis Universitas Udayana (Unud), Bali, Indonesia \\ email: dindasukma96@gmail.com
}

\begin{abstract}
ABSTRAK
Seiring perkembangan bisnis kuliner yang cukup pesat menuntut pebisnis untuk berkembang dan berinovasi suatu produk yang sesuai dengan kebutuhan dan selera konsumen. Salah satu produk yang sedang unggul saat ini adalah Warunk Upnormal. Tujuan dari penelitian ini untuk menguji pengaruh Inovasi Produk terhadap Loyalitas Pelanggan melalui kepuasan konsumen Warunk Upnormal. Variabel yang diteliti pada penelitian ini adalah variabel Inovasi produk, kepuasan konsumen dan Loyalitas Pelanggan. Jumlah sampel yang diambil sebanyak 100 konsumen Warunk Upnormal dengan metode purposive sampling yang memiliki kriteria pernah membeli produk dan berkunjung ke Warunk Upnormal, berdomisili di Kota Denpasar, dan berpendidikan terakhir SMA. Data dikumpulkan melalui penyebaran kuesioner. Teknik analisis yang digunakan adalah path analysis dan didukung dengan uji sobel. Berdasarkan hasil analisis ditemukan bahwa variabel inovasi produk berpengaruh positif dan signifikan terhadap kepuasan pelanggan Warunk Upnormal, variabel inovasi produk berpengaruh positif dan signifikan terhadap loyalitas pelanggan Warunk Upnormal, variabel kepuasan pelanggan berpengaruh positif dan signifikan terhadap loyalitas pelanggan Warunk Upnormal, serta variabel kepuasan pelanggan memediasi pengaruh inovasi produk terhadap loyalitas pelanggan Warunk Upnormal di Kota Denpasar.

Kata Kunci: inovasi produk; kepuasan konsumen; loyalitas pelanggan; warunk upnormal.
\end{abstract}

\section{ABSTRACT}

As the development of the culinary business is quite rapid, it requires businesses to develop and innovate a product that suits the needs and tastes of consumers. One of the products that is currently superior is Warunk Upnormal. The purpose of this study is to examine the effect of Product Innovation on Customer Loyalty through customer satisfaction Warunk Upnormal.The variables studied in this study were product innovation, customer satisfaction and customer loyalty. The number of samples taken is 100 consumers of Warunk Upnormal with a purposive sampling method that has the criteria of ever buying a product and visiting the Warunk Upnormal, domiciled in the city of Denpasar, and educated last high school. Data was collected through questionnaires. The analysis technique used is path analysis and supported by the sobel test.Based on the results of the analysis found that product innovation variables have a positive and significant effect on Warunk Upnormal customer satisfaction, product innovation variables have a positive and significant effect on Warunk Upnormal customer loyalty, customer satisfaction variables have a positive and significant effect on Warunk Upnormal customer loyalty, and customer satisfaction variables mediate influence product innovation towards customer loyalty in the City of Denpasar.

Keywords: product innovation; consumer satisfaction; customer loyalty; warunk upnormal. 


\section{PENDAHULUAN}

Kondisi persaingan didunia bisnis kini memang sangat ketat, terutama dalam bisnis kuliner yang berada di Bali, khususnya di wilayah Denpasar. Badan pusat penelitian mencatat adanya penurunan dan peningkatan bisnis kuliner yang terjadi dari tahun 2012-2017. Salah satu cara untuk memenangkan persaingan yang ketat terletak pada kemampuan perusahaan untuk menciptakan keunggulan bersaing yang didapatkan dengan memberikan nilai yang lebih kepada pelanggan dari apa yang diberikan oleh pesaing. Perusahaan akan mengupayakan agar pelanggan yang sudah diciptakan dapat dipertahankan selamanya. Loyalitas pelanggan dalam jangka panjang menjadi tujuan bagi perencanaan pasar strategis.

Perusahaan tidak mungkin terus menerus melakukan promosi yang dapat menghabiskan banyak biaya. Karena para pengusaha atau perusahaan menyadari betapa pentingnya pelanggan bagi kelangsungan usaha mereka (Henriawan, 2015). Komitmen yang kuat menunjukkan "sikap" untuk sebuah merek bahwa benar loyalitas ada (Pishgar et al., 2013).

Untuk mengembangkan loyalitas pelanggan, maka perlu diketahui alasan sesungguhnya yang mempengaruhi pelanggan menjadi loyal dengan mengukur nilai loyalitas dan melihat pengaruh kepuasan pelanggan. Kepuasan pelanggan dapat memengaruhi niat dan perilaku pembelian kembali (Te et al., 2013). Kepuasan pelanggan didefinisikan oleh Kotler dan Keller, (2016:153) yang menyatakan bahwa "Satisfactionis a person's feelings of pleasure or disappointment that result from comparing a product or service's perceived performance (or outcome) to expectations". Pelanggan dapat mengalami salah satu dari tiga tingkat kepuasan umum yaitu jika kinerja dibawah harapan, pelanggan akan merasa kecewa tetapi jika kinerja sesuai dengan harapan pelanggan akan merasa puas dan apabila kinerja bisa melebihi harapan maka pelanggan akan merasa sangat puas senang atau gembira. Kepuasan atau ketidakpuasan adalah respon pelanggan terhadap evaluasi ketidaksesuaian yang dirasakan antara harapan sebelumnya dengan kinerja aktual produk (Sawitri, 2013). Adanya kepuasan pelanggan, maka kelangsungan usaha pun akan terjaga. Penelitian yang dilakukan Agung (2016) menunjukkan bahwa kepuasan pelanggan memiliki pengaruh yang signifikan terhadap loyalitas pelanggan dengan nilai probabilitas kepuasan terhadap loyalitas pelanggan sebesar $0,000(\mathrm{p} \leq 0,05)$. Perusahaan harus mulai memikirkan pentingnya kepuasan pelanggan secara lebih matang, karena kini disadari bahwa pelayanan dan kepuasan pelanggan merupakan aspek vital dalam bertahan didunia bisnis untuk memenangkan persaingan (Sumertana, 2016).

Salah satu cara yang dapat memenangkan persaingan yaitu dengan melakukan inovasi produk. Menurut Alifuddin \& Razak (2015:121) Inovasi merupakan sesuatu yang berkenaan dengan barang, jasa atau ide yang dirasakan baru oleh seseorang. Inovasi produk adalah sesuatu yang dapat dilihat sebagai kemajuan fungsional produk yang dapat membawa produk selangkah lebih maju dibandingkan dengan produk pesaingnya (Sukarmen, 2013). Inovasi produk adalah salah satu faktor yang paling diandalkan oleh seorang pemasar dalam memasarkan suatu produk. Inovasi akan meningkatkan nilai tambah suatu produk, inovasi akan menciptakan suatu produk baru yang dapat memberikan solusi yang lebih baik bagi pemecahan masalah yang dihadapi pelanggan (Masda, 2012). Inovasi dalam 
kewirausahaan terbagi atas dua tipe inovasi yang membentuk keuntungan bagi suatu usaha dengan cara yang berbeda yaitu inovasi produk dan inovasi proses McDaniel (2002:105) dikutip dari pendapat Chyntia \& Tawas (2014:1217).

Perusahaan harus memberikan pemikiran-pemikiran baru, gagasan baru, dan menawarkan produk yang inovatif dalam rangka memuaskan pelanggan. Inovasi dapat mencakup banyak bidang proses bisnis, seperti produk, proses atau layanan, teknologi, organisasi, pemasaran, dan strategi perusahaan (Fatkhurrohman, 2011). Penelitian yang dilakukan caesar (2017) menunjukkan bahwa inovasi produk berpengaruh positif dan signifikan terhadap loyalitas pelanggan. Menciptakan inovasi, sebuah produk dapat memiliki posisi strategi di pasar, memiliki life cycle yang lebih panjang, dan dapat menahan serangan dari para pesaing serta dapat memenuhi keinginan pasar (pelanggan).

Seiring perkembangan bisnis kuliner khususnya di Kota Denpasar, semakin meningkatnya persaingan di antara restaurant atau warung di Kota Denpasar. Salah satu usaha kuliner yang ada di Kota Denpasar adalah Warunk Upnormal. Warunk Upnormal dikenal sebagai pelopor indomie kekinian dan menjadi warung yang menyajikan hingga 100 colokan untuk pengunjung yang datang. Warunk upnormal menginovasikan menu indomie yang biasa menjadi unik dan mempunyai ciri khasnya dan tidak ada di warung-warung lainnya.

Warunk Upnormal menyajikan konsep warung dengan nuansa yang menarik dengan fasilitas wifi, TV, parkir, permainan seperti UNO, Bridge Card, dan yang lainnya. Citra yang sudah dibentuk oleh Warunk Upnormal sebagai warung dengan konsep yang unik dan menarik telah berhasil membuat pelanggan menjadi loyal dalam membeli produk mereka.

Warunk Upnormal terus menginovasikan menu-menu masakannya tanpa mengurangi cita rasa yang khas dari masakannya untuk menghadapi persaingan yang ketat. Menu-menu yang berinovasi, para pelanggan akan merasa puas memilih menu sesuai selera. Warunk Upnormal akan membuat para pelanggannya merasa puas dengan apa yang ditawarkannya dan sebisa mungkin akan melayani pelanggannya dengan baik agar para pelanggannya bisa berkunjung kembali lagi ke sana.

Tabel 1.

\section{Hasil Pra Survey}

\begin{tabular}{lllll}
\hline NO & \multicolumn{1}{c}{ Variabel } & \multicolumn{1}{c}{ Pertanyaan } & Ya & Tidak \\
\hline 1 & Kepuasan & $\begin{array}{l}\text { Saya merasa produk dari Warunk Upnormal sudah } \\
\text { Pelanggan }\end{array}$ & 6 & 4 \\
2 & Inovasi Produk & $\begin{array}{l}\text { Warunk Upnormal menyajikan menu makanan } \\
\text { dengan citarasa khas daerah }\end{array}$ & 7 \\
3 & Loyalitas & $\begin{array}{l}\text { Saya berniat untuk membeli kembali produk } \\
\text { Warunk Upnormal }\end{array}$ & 3 \\
\hline
\end{tabular}

Sumber : Data primer diolah, 2018

Penelitian ini diawali dengan melakukan pra survey terhadap 10 responden yang merupakan mahasiswa, dengan hasil sebagian responden menyatakan akan kembali ke warunk upnormal, dikarenakan pelanggan puas dengan inovasi menumenu yang disediakan. Harga Makanan di warunk upnormal yang relative murah juga dapat menjangkau kalangan menengah ke bawah. Ketika pelanggan merasa 
puas dengan makanan yang ada di warunk upnormal maka mampu meningkatkan kepercayaannya terhadap warunk upnormal sehingga membuat pelanggan loyal.sebagian responden menyatakan tidak akan kembali ke Warunk Upnormal, karena makanan yang disediakan tidak sesuai harapan sehingga pelanggan tidak puas dengan apa yang disajikan. Fasilitas seperti permainan yang sudah rusak dan tidak layak pakai juga dapat menurunkan kepuasan pelanggan tersebut.

Berdasarkan latar belakang yang ada diatas maka penelitian ini ingin menguji bagaimana peran kepuasan pelanggan dalam memediasi pengaruh inovasi produk terhadap loyalitas pelanggan (studi pada pelanggan Warunk Upnormal di Kota Denpasar) maka rumusan masalah penelitian ini (1) Bagaimana pengaruh Inovasi Produk terhadap Loyalitas Pelanggan Warunk Upnormal? (2) Bagaimana pengaruh Inovasi Produk terhadap Kepuasan Pelanggan Warunk Upnormal? (3) Bagaimana pengaruh Kepuasan Pelanggan terhadap Loyalitas Pelanggan Warunk Upnormal? (4) Bagaimana peran Kepuasan Pelanggan Memediasi Pengaruh Inovasi Produk terhadap Loyalitas Pelanggan?.

Maka yang menjadi tujuan penelitian ini (1) Untuk menjelaskan pengaruh Inovasi produk terhadap Loyalitas pelanggan Warunk upnormal (2) Untuk menjelaskan pengaruh Inovasi Produk terhadap Kepuasan Pelanggan Warunk Upnormal (3) Untuk menjelaskan pengaruh Kepuasan Pelanggan terhadap Loyalitas Pelanggan Warunk Upnormal (4) Untuk menjelaskan peran Kepuasan Pelanggan memediasi Pengaruh Inovasi Produk terhadap Loyalitas Pelanggan.

Manfaat penelitian ini diharapkan nantinya dapat berguna bagi semua pihak yang membutuhkan baik secara praktis maupun teoritis. Adapun kegunaan dari penelitian ini (1) Penelitian ini dapat dijadikan pedoman bagi perusahaan dalam menetapkan kebijakan di masa yang akan datang yang berkaitan dengan peran kepuasan pelanggan dalam memediasi pengaruh inovasi produk terhadap loyalitas pelanggan (2) Penelitian ini dapat menambah pengetahuan, wawasan, serta informasai yang dibutuhkan dalam studi akademik suatu saat nanti. Selain itu, penelitian ini juga diharapkan dapat dijadikan sebagai referensi untuk penelitian selanjutnya yang bertujuan untuk mengembangkan ilmu pengetahuan terutama mengenai peran kepuasan pelanggan dalam memediasi pengaruh inovasi produk terhadap loyalitas pelanggan.

Inovasi produk merupakan salah satu faktor persaingan yang paling penting untuk mencapai kesuksesan dimana akhir-akhir ini lingkungan bisnis selalu berubah dengan cepat. Pengusaha yang mampu menciptakan jenis barang baru akan memberi keuntungan bagi pasar dan menarik pelanggan baru serta meningkatkan kinerja perusahaan (Hafeez \& bakhtiar, 2012). Secara sederhana, inovasi dapat diartikan sebagai terobosan yang berkaitan dengan produk-produk baru. Sebuah perusahaan harus kompetitif dalam menjalankan usahanya, inovasi dan daya saing merupakan hal yang saling berkaitan sangat erat. Inovasi merupakan hal mengimplementasikan dan mengkreasikan sesuatu agar menjadi sesuatu yang baru agar pelanggan semakin tertarik dengan produk yang ditawarkan. Saat ini lingkungan bisnis dari local menjadi global, siapapun yang terkuat dialah yang menjadi unggul dalam persaingan.Perusahaan diharapkan mampu memberikan keunggulan yang kompetitif, tidak hanya satu tetapi juga sulit untuk ditiru. 
Mengingat perubahan selera yang cepat dalam teknologi dan persaingan, perusahaan tidak bisa hanya mengandalkan produk yang ada untuk mempertahankan pertumbuhan atau untuk mempertahankan laba. Perusahaan yang memiliki harapan untuk mempertahankan pasar dan laba kinerja bisa dengan melakukan inovasi produk yang berkelanjutan.

Kepuasan pelanggan didefinisikan oleh Kotler \& Keller (2016:153) yang menyatakan bahwa 'Satisfactionis a person's feelings of pleasure or disappointment that result from comparing a product or service's perceived performance (or outcome) to expectations". Pelanggan dapat mengalami salah satu dari tiga tingkat kepuasan umum yaitu jika kinerja dibawah harapan, pelangganakan merasa kecewa tetapi jika kinerja sesuai dengan harapan pelanggan akan merasa puas dan apabila kinerja bisa melebihi harapan maka pelanggan akan merasa sangat puas senang atau gembira. Beberapa pengertian kepuasan pelanggan yang mengatakan bahwa kepuasan merupakan bagaimana pelanggan merasa puas apabila sesuai dengan harapan pelanggan atau sudah terlampaui (Bayraktar et al., 2012; Jian, Xin et al, 2009; Shanin et al., 2011). Kepuasan pelanggan merupakan suatu penilaian emosional dari pelanggan setelah pelanggan menggunakan suatu produk, dimana harapan dan kebutuhan pelanggan yang menggunakannya terpenuhi. Pelanggan yang puas adalah pelanggan yang akan berbagi kepuasan dengan pemasar atau penyedia jasa, bahkan dengan pelanggan lain, dan akan membawa dampak pada kegiatan pembelian berulang. Hal ini akan menjadi referensi bagi perusahaan. Pelanggan bukan hanya dipuaskan dengan produk barang atau jasa yang mereka konsumsi, tetapi dari pengalaman dan emosional yang mereka dapatkan dari awal mereka berangkat hingga pulang. Perusahaan harus melakukan pemasaran dengan banyak menyentuh sisi psikologi pelanggan, sehingga siapapun yang pernah berkunjung disana akan memperoleh pengalaman yang tidak biasa. Oleh karena itu, baik pelanggan maupun pemasar akan sama-sama diuntungkan apabila kepuasan pelanggan itu akan tercapai.

Kotler \& Keller (2016:153) menyatakan bahwa loyalitas adalah komitmen yang dipegang dalam melakukan pembelian ulang (repurchase) atau berlangganan suatu produk atau jasa yang disukai di masa depan meskipun pengaruh situasi dan upaya pemasaran memiliki potensi untuk menyebabkan perilaku untuk beralih. Menciptakan hubungan yang erat dengan pelanggan adalah mimpi semua pemasar. Menurut Ali (2013:83) loyalitas pelanggan terhadap suatu merek terjadi karena adanya pengaruh kepuasan dan ketidakpuasan dengan merek tersebut yang terakumulasikan secara terus-menerus, di samping adanya persepsi kualitas produk. Saat loyalitas pelanggan dapat dibangun, akan memberikan manfaat yang besar bagi perusahaan, diantaranya : (1)Mengurangi biaya pemasaran (2) Trade leverage (3) Menarik pelanggan baru (4) Merespons ancaman pesaing (5) Nilai kumulatif bisnis berkelanjutan

Kerangka diatas diambil berdasarkan judul penelitian Peran Kepuasan Pelanggan dalam Memediasi Pengaruh Inovasi Produk terhadap Loyalitas Pelanggan (Studi pada Pelanggan Warunk Upnormal) sehingga dapat di ambil variabel yaitu inovasi, kepuasan pelanggan dan loyalitas pelanggan 


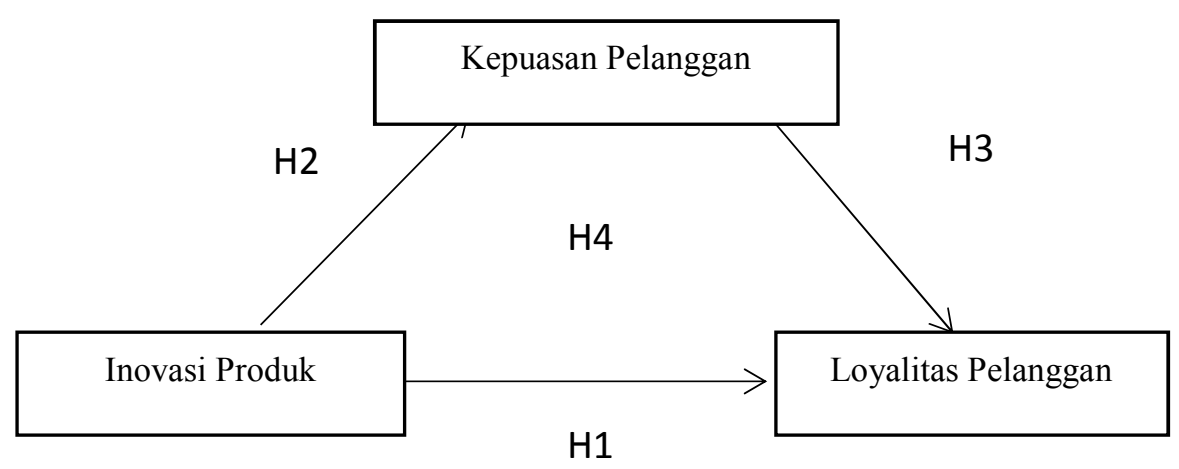

Gambar 2. Kerangka Konseptual

Dalam hasil penelitian (Caesar, 2017) menunjukkan bahwa Inovasi produk berpengaruh positif dan signifikan terhadap loyalitas pelanggan. Begitu juga pada hasil penelitian (Roring dkk., 2014) yang menunjukkan bahwa inovasi produk berpengaruh positif dan signifikan terhadap loyalitas pelanggan. Berdasarkan kerangka berfikir diatas maka dapat diajukan hipotesis sebagai berikut :

$\mathrm{H}_{1}$ : Inovasi Produk berpengaruh positif dan signifikan terhadap Loyalitas Pelanggan.

Menurut penelitian Agung (2016) dan Tahir et al. (2012) menunjukkan bahwa Inovasi Produk berpengaruh positif dan signifikan terhadap kepuasan pelanggan, artinya jika semakin tinggi inovasi produk, maka semakin tinggi pula kepuasan pelanggan yang didapat. Begitu pula menurut (Sukarmen, 2013) dan Sujadi \& Wahyono (2015) bahwa inovasi produk berpengaruh positif dan signifikan terhadap kepuasan pelanggan. Berdasarkan kerangka berfikir di atas maka dapat diajukan hipotesis sebagai berikut :

$\mathrm{H}_{2}$ : Inovasi Produk berpengaruh positif dan signifikan terhadap Kepuasan pelanggan.

Menurut Nugroho (2013) Pelanggan akan loyal terhadap suatu produk atau jasa yang ditawarkan bila ia mendapatkan kepuasan dari produk atau jasa tersebut. Penelitian (Hidayat, 2014; Lee, 2013; Purwa, 2017) menunjukkan bahwa Kepuasan Pelanggan berpengaruh Positif dan signifikan terhadap Loyalitas pelanggan. Berdasarkan kerangka berfikir diatas maka dapat diajukan hipotesis sebagai berikut $\mathrm{H}_{3}$ : Kepuasan Pelanggan berpengaruh positif dan signifikan terhadap Loyalitas Pelanggan.

Agung (2016) dalam penelitiannya menunjukan bahwa inovasi produk memiliki pengaruh positif dan signifikan terhadap kepuasan pelanggan. Penelitian yang juga dilakukan oleh Singh \& Thakur (2012) mendapatkan hasil bahwa Kepuasan pelanggan memiliki pengaruh positif yang signifikan dalam memediasi hubungan kualitas layanan terhadap loyalitas. Berdasarkan hasil penelitian sebelumnya diatas maka dapat dibangun hipotesis sebagai berikut:

$\mathrm{H}_{4}$ : Kepuasan Pelanggan Memediasi pengaruh Inovasi Produk berpengaruh positif dan signifikan terhadap Loyalitas Pelanggan. 


\section{METODE PENELITIAN}

Penelitian asosiatif ini dilakukan di Warunk Upnormal Bali, yang berada di lokasi Jl. Raya Puputan No. 50, Renon. Dengan subjek penelitian adalah Pelanggan Warunk Upnormal dan objek penelitianya adalah variabel Inovasi produk, kepuasan pelanggan dan loyalitas pelanggan. Jenis data yang digunakan dalam penelitian ini adalah data kualitatif dan data kuantitatif.

Data yang digunakan adalah data primer dan sekunder dengan populasi penelitian adalah seluruh pelanggan kota Denpasar yang sudah pernah berkunjung ke Warunk Upnormal dan membeli produknya dengan jumlah yang tidak diketahui secara pasti (infinite). Penelitian ini bertujuan untuk mengetahui peran kepuasan pelanggan dalam memediasi pengaruh inovasi produk terhadap loyalitas pelanggan pada Pelanggan Warunk Upnormal. Terdapat tiga variable dalam penelitian ini, yaitu loyalitas pelanggan $\left(\mathrm{Y}_{2}\right)$, kepuasan pelanggan $\left(\mathrm{Y}_{1}\right)$, dan inovasi produk $\left(\mathrm{X}_{1}\right)$.

Tabel 1.

Indikator Variabel Penelitian

\begin{tabular}{|c|c|c|c|}
\hline No & Variabel & Indikator & Referensi \\
\hline 1 & $\begin{array}{l}\text { Inovasi Produk } \\
\text { (X) }\end{array}$ & $\begin{array}{l}\text { 1) Penambahan varian produk. } \\
\text { 2) Perusahaan selalu meningkatkan } \\
\text { kualitas } \\
\text { 3) Perusahaan selalu menggunakan } \\
\text { bahan baku yang baru }\end{array}$ & $\begin{array}{l}\text { Atalay et } a l, 2013) \text {, } \\
\text { Cahyo \& Harjanti } \\
(2013)\end{array}$ \\
\hline 2 & $\begin{array}{l}\text { Kepuasan } \\
\text { (Y2) }\end{array}$ & $\begin{array}{l}\text { 1) Terpenuhinya Harapan } \\
\text { 2) Rasa Senang dan Puas } \\
\text { 3) Kesediaan Merekomendasikan } \\
\text { 4) Kepuasan secara menyeluruh }\end{array}$ & $\begin{array}{l}\text { (Santoso, 2016:99) } \\
\text { dan (Kotler, 2012) }\end{array}$ \\
\hline 3 & $\begin{array}{l}\text { Loyalitas } \\
\text { Pelanggan } \\
(\mathrm{Y} 1)\end{array}$ & $\begin{array}{l}\text { 1) menjadi pilihan pertama } \\
\text { 2) transaksi ulang } \\
\text { 3) Say positive things }\end{array}$ & $\begin{array}{lr}\text { Hadinata } & \text { (2013), } \\
\text { Lupiyodi } & (2013), \text { dan } \\
\text { Zeithaml et al } \\
(2009: 47)\end{array}$ \\
\hline
\end{tabular}

Sumber: Dikembangkan dari penelitian sebelumnya

Penelitian ini menggunakan teknik pengumpulan sampel non probability sampling dengan metode purposive sampling yaitu teknik penentuan sampel dengan pertimbangan tertentu. Jumlah anggota sampel atau besarnya sampel ditetapkan dengan pertimbangan yang menyatakan bahwa, penelitian ini menggunakan 10 indikator sehingga banyaknya responden yang sebagai sampel adalah $10 \times 10=100$ responden. Adapun kriteria sebagai responden adalah Responden yang sudah pernah mengunjungi dan membeli produk Warunk Upnormal minimal tiga kali dan Responden berpendidikan minimal SMA dan sederajat.

Karakteristik responden merupakan data responden yang dikumpulkan untuk mengetahui profil responden penelitian, dapat diketahui karakteristik responden yang meliputi empat aspek yaitu umur, jenis kelamin, pendidikan, dan pekerjaan.

Berdasarkan Tabel 2. Menurut kelompok usia, responden di domisili oleh responden kelompok usia 21-25 tahun sebesar 56\%. Proporsi demikian menunjukkan bahwa usia tersebut merupakan usia mahasiswa yang senang 
berkumpul di tempat yang memiliki fasilitas memadai dan mempunyai harga makanan yang terjangkau.

Tabel 2.

Pelanggan Warunk Upnormal Menurut Usia pada Masyarakat di Kota Denpasar

\begin{tabular}{|c|c|c|}
\hline \multirow{2}{*}{$\begin{array}{l}\text { Kelompok Umur } \\
\text { (Tahun) }\end{array}$} & \multicolumn{2}{|c|}{ Jumlah Responden } \\
\hline & Frekuensi & Persentase (\%) \\
\hline $16-20$ & 31 & 31 \\
\hline $21-25$ & 56 & 56 \\
\hline$>26$ & 13 & 13 \\
\hline Jumlah & 100 & 100 \\
\hline
\end{tabular}

Sumber : Data diolah, 2018

Tabel 3.

Pelanggan Warunk Upnormal Menurut Jenis Kelamin Pada Masyarakat di Kota Denpasar

\begin{tabular}{clcc}
\hline No & Jenis Kelamin & \multicolumn{2}{c}{ Jumlah Responden } \\
& & Frekuensi & Persentase(\%) \\
\hline 1 & Laki-Laki & 42 & 42 \\
2 & Perempuan & 58 & 58 \\
Jumlah & $\mathbf{1 0 0}$ & $\mathbf{1 0 0}$ \\
\hline
\end{tabular}

Sumber :Data diolah, 2018

Sebanyak 100 orang dengan persentase laki-laki sebesar $42 \%$, sedangkan perempuan sebesar 58\%. Disimpulkan bahwa Warunk Upnormal dapat diperuntukan bagi pria maupun wanita.

Tabel 4.

Pelanggan Warunk Upnormal Menurut Tingkat Pendidikan Pada Masyarakat di Kota Denpasar

\begin{tabular}{clcc}
\hline No & \multicolumn{1}{c}{ Tingkat Pendidikan } & \multicolumn{2}{c}{ Jumlah Responden } \\
\cline { 3 - 4 } & & Frekuensi & Persentase(\%) \\
\hline 1. & SMA/SLTA Sederajat & 32 & 32 \\
2. & Diploma 3 (D3) & 21 & 21 \\
3. & Sarjana (S1) & 47 & 47 \\
Jumlah & $\mathbf{1 0 0}$ & $\mathbf{1 0 0}$ \\
Sumber $:$ Data diolah, 2018 & &
\end{tabular}

Responden yang memiliki tingkat pendidikan Sarjana (S1) sebesar 47\%, sedangkan dengan persentase terkecil berpendidikan Diploma sebesar 21\%. Disimpulkan bahwa masyarakat Kota Denpasar berdasarkan pendidikan sebagian besar pelanggan Warunk Upnormal berpendidikan sarjana (S1).

Sebagian besar responden memiliki pekerjaan sebagai pelajar/mahasiswa yaitu sebesar $66 \%$, sedangkan responden dengan persentase terkecil memiliki pekerjaan Pegawai Swasta yaitu 7\%. Disimpulkan bahwa masyarakat Kota Denpasar yang memiliki pekerjaan sebagai pelajar/mahasiswa mendominasi pelanggan Warunk Upnormal.

Metode pengumpulan data dalam penelitian ini, melalui instrument penelitian berupa kuesioner. Pernyataan dalam kuesioner yang diukur dengan menggunakan skala likert dengan skala 1 sampai dengan 5 dengan keterangan : (1) skor lima 
artinya jawaban sangat setuju dengan kode SS, (2) skor empat artinya jawaban setuju dengan kode S, (3) skor tiga artinya jawaban cukup setuju dengan kode CS, (4) skor dua artinya jawaban tidak setuju dengan kode TS, (5) skor satu artinya jawaban sangan tidak setuju dengan kode STS (Sugiyono, 2016:107)

Tabel 5.

Pelanggan Warunk Upnormal Menurut Jenis Pekerjaan Pada Masyarakat di Kota Denpasar

\begin{tabular}{llcc}
\hline \multirow{2}{*}{ No } & Jenis Pekerjaan & \multicolumn{2}{c}{ Jumlah Responden } \\
\cline { 3 - 4 } & & Frekuensi & Persentase(\%) \\
\hline 1. & Pelajar/Mahasiswa & 66 & 66 \\
2. & PNS & 12 & 12 \\
3. & Wiraswasta & 15 & 15 \\
4. & Pegawai Swasta & 7 & 7 \\
Jumlah & $\mathbf{1 0 0}$ & $\mathbf{1 0 0}$ \\
\hline
\end{tabular}

Sumber :Data diolah, 2018

\begin{tabular}{lll}
\multicolumn{3}{c}{$\begin{array}{c}\text { Tabel 6. } \\
\text { Penentuan Skor }\end{array}$} \\
\hline Simbol & Alternatif Jawaban & Skor \\
\hline SS & Sangat Setuju & 5 \\
S & Setuju & 4 \\
CS & Cukup Setuju & 3 \\
TS & Tidak Setuju & 2 \\
STS & Sangat Tidak Setuju & 1 \\
\hline Sumber : Sugiyono, 2016 &
\end{tabular}

Instrumen penelitian ini menggunakan data primer melalui kuesioner, maka perlu pengujian agar instrumen yang digunakan dalam penelitian ini dapat berfungsi dengan baik dan benar. Untuk itu dibutuhkan uji validitas dan reliabilitas agar instrumen tersebut mampu mengumpulkan data yang benar-benar menggambarkan fenomena yang terjadi.

Teknik Analisis Data yang digunakan adalah Uji Analisis Jalur (Path Analysis), Uji Asumsi Klasik dan Uji Sobel (Sobel Test). Model regresi dikatakan model yang baik apabila model tersebut bebas dari asumsi klasik statistik. Suatu model secara teoritis akan menghasilkan nilai parameter penduga yang tepat bila memenuhi persyaratan asumsi klasik regresi, yaitu meliputi uji normalitas, multikolinearitas, dan heterokedastisitas.

\section{HASIL DAN PEMBAHASAN}

Setiap item pertanyaan dari masing - masing variabel pada kuisioner yaitu Inovasi Produk, Kepuasan Pelanggan dan Loyalitas Pelanggan memiliki nilai koefisien korelasi yang lebih besar 0,3 sehingga pertanyaan dalam kuisioner yang digunakan dinyatakan valid.

Nilai Cronbach's Alpha yang didapatkan masing - masing variabel pada kuisioner Variabel Inovasi Produk sebesar 0.866, Kepuasan Pelanggan sebesar 0.715 dan Loyalitas Pelanggan sebesar 0.830. Nilai Cronbach's Alpha yang dihasilkan setiap variabel yang digunakan lebih besar dari 0.6 sehingga dapat 
disimpulkan bahwa kuisioner yang digunakan sudah reliabel. Karena kuisioner sudah dinyatakan valid dan reliabel, maka kuisioner dapat digunakan sebagai alat ukur dan analisa lebih lanjut. Suatu variabel dikatakan reliabel jika memberikan nilai Cronbach Alpha $(\alpha)>0,60$ (Ghozali, 2013:47).

Tabel 7.

Hasil Uji Validitas

\begin{tabular}{|c|c|c|c|c|}
\hline Variabel & Indikator & Nilai r Hitung & Nilai r Tabel & Keterangan \\
\hline Inovasi Produk & $\mathrm{X} 1.1$ & 0.899 & 0.300 & Valid \\
\hline \multirow{2}{*}{ (X1) } & $\mathrm{X} 1.2$ & 0.897 & 0.300 & Valid \\
\hline & $\mathrm{X} 1.3$ & 0.855 & 0.300 & Valid \\
\hline Kepuasan & Y1.1 & 0.672 & 0.300 & Valid \\
\hline \multirow[t]{3}{*}{ Pelanggan (Y1) } & Y1.2 & 0.804 & 0.300 & Valid \\
\hline & Y1.3 & 0.817 & 0.300 & Valid \\
\hline & Y1.4 & 0.668 & 0.300 & Valid \\
\hline Loyalitas & Y2.1 & 0.878 & 0.300 & Valid \\
\hline \multirow[t]{2}{*}{ Pelanggan (Y2) } & Y2.2 & 0.950 & 0.300 & Valid \\
\hline & Y2.3 & 0.770 & 0.300 & Valid \\
\hline
\end{tabular}

Sumber :Data diolah, 2018

Tabel 8.

Hasil Uji Reliabilitas

\begin{tabular}{lccc}
\hline Variabel Penelitian & $\begin{array}{c}\text { Nilai Cronbach's } \\
\text { Apha }\end{array}$ & $\begin{array}{c}\text { Syarat Cronbach's } \\
\text { Apha }\end{array}$ & Keterangan \\
\hline $\begin{array}{l}\text { Inovasi Produk (X1) } \\
\begin{array}{l}\text { Kepuasan Pelanggan } \\
\text { (Y1) }\end{array}\end{array} \quad 0.866$ & 0.600 & Reliabel \\
$\begin{array}{l}\text { Loyalitas Pelanggan } \\
\text { (Y2) }\end{array}$ & 0.715 & 0.600 & Reliabel \\
\hline
\end{tabular}

Sumber : Data diolah, 2018

Berdasarkan hasil tabulasi data yang dijawab oleh 100 responden. menunjukkan bahwa 3 (tiga) pernyataan mengenai inovasi produk memperoleh nilai rata - rata 3,87 dan masuk dalam kriteria dengan kategori penilaian 3,40 - 4,19 yaitu Baik. Hal ini berarti bahwa responden pelanggan Warunk Upnormal di Kota Denpasar dalam penelitian ini setuju menilai inovasi produk yang mereka rasakan ketika berkunjung ke Warunk Upnormal, dan responden juga memiliki penilaian yang baik terhadap inovasi produk tersebut.

Berdasarkan hasil tabulasi data pada jawaban responden yaitu 4 (empat) pernyataan tentang kepuasan pelanggan pada pelanggan Warunk Upnormal di Kota Denpasar yang dijawab oleh 100 responden dan memperoleh nilai rata - rata 3,80. Hal ini berarti bahwa responden pelanggan Warunk Upnormal di Kota Denpasar dalam penelitian ini setuju menilai kepuasan pelanggan yang merupakan persepsi dan keyakinan yang terbenak dalam pikiran pelanggan ketika mendengar Warunk Upnormal, dan responden juga memiliki penilaian kepuasan pelanggan yang baik terhadap warunk upnormal.

Berdasarkan hasil tabulasi data pada jawaban responden yaitu 3 (tiga) pernyataan tentang loyalitas pelanggan pada pelanggan Warunk Upnormal di Kota Denpasar yang dijawab oleh 100 responden. Menunjukkan bahwa 3 (tiga) 
pernyataan mengenai loyalitas pelanggan memperoleh nilai rata - rata 3,80 dan hal ini berarti bahwa responden pelanggan Warunk Upnormal di Kota Denpasar dalam penelitian ini setuju menilai loyalitas pelanggan warunk upnormal,karena dapat membuat warunk upnormal meningkat dan pelanggan yang loyal akan menginformasikan tentang Warunk Upnormal ke orang-orang sekitarnya.

Tabel 9.

\begin{tabular}{|c|c|c|c|c|c|c|c|c|c|}
\hline \multirow{2}{*}{ No. } & \multirow{2}{*}{$\begin{array}{c}\text { Pernyataan Tentang Kualitas } \\
\text { Produk (X) }\end{array}$} & \multicolumn{5}{|c|}{ Jawaban Responden } & \multirow{2}{*}{$\begin{array}{c}\text { Jml } \\
\text { Rs } \\
\text { p }\end{array}$} & \multirow{2}{*}{$\begin{array}{l}\text { Rata- } \\
\text { Rata }\end{array}$} & \multirow{2}{*}{ Ket } \\
\hline & & 1 & 2 & 3 & 4 & 5 & & & \\
\hline 1 & $\begin{array}{l}\text { Warunk Upnormal menyajikan } \\
\text { menu makanan dengan citarasa } \\
\text { khas daerah (X.1) }\end{array}$ & 1 & 6 & 20 & 57 & 16 & 100 & 3,81 & Baik \\
\hline 2 & $\begin{array}{l}\text { Warunk Upnormal selalu } \\
\text { meningkatkan kualitas menu } \\
\text { makanan dan pelayanan (X.2) }\end{array}$ & 1 & 7 & 17 & 52 & 23 & 100 & 3,89 & Baik \\
\hline 3 & $\begin{array}{l}\text { Warunk Upnormal selalu } \\
\text { menyajikan menu makanan yang } \\
\text { fresh (X.3) }\end{array}$ & 2 & 4 & 21 & 46 & 27 & 100 & 3,92 & Baik \\
\hline & Rata-rata & & & & & & & 3,87 & Baik \\
\hline
\end{tabular}

Sumber: Data primer diolah, 2018

Tabel 10.

Deskripsi Jawaban Responden Mengenai Penilaian Terhadap Variabel Kepuasan Pelanggan

\begin{tabular}{|c|c|c|c|c|c|c|c|c|c|}
\hline \multirow{2}{*}{ No. } & \multirow{2}{*}{$\begin{array}{c}\text { Pernyataan Tentang Kepuasan } \\
\text { Pelanggan (Y1) }\end{array}$} & \multicolumn{5}{|c|}{ Jawaban Responden } & \multirow{2}{*}{$\begin{array}{l}\text { Jml } \\
\text { Resp }\end{array}$} & \multirow{2}{*}{$\begin{array}{l}\text { Rata- } \\
\text { Rata }\end{array}$} & \multirow{2}{*}{ Ket } \\
\hline & & 1 & 2 & 3 & 4 & 5 & & & \\
\hline 1 & $\begin{array}{l}\text { Saya merasa produk dari Warunk } \\
\text { Upnormal sudah sesuai dengan } \\
\text { harapan saya (Y1.1) }\end{array}$ & 6 & 15 & 34 & 39 & 6 & 100 & 3,24 & $\begin{array}{c}\text { Cukup } \\
\text { Baik }\end{array}$ \\
\hline 2 & $\begin{array}{l}\text { Saya merasa senang setelah } \\
\text { mengunjungi dan mencoba produk } \\
\text { Warunk Upnormal (Y1.2) }\end{array}$ & 2 & 2 & 26 & 54 & 16 & 100 & 3,80 & Baik \\
\hline 3 & $\begin{array}{l}\text { Saya merasa puas secara } \\
\text { keseluruhan terhadap } \\
\text { Warunk Upnormal (Y1.3) }\end{array}$ & 1 & 0 & 20 & 54 & 25 & 100 & 4,02 & Baik \\
\hline 4 & $\begin{array}{lr}\text { Saya berniat } & \text { untuk } \\
\text { merekomendasikan } & \text { produk } \\
\text { Warunk Upnormal kepada } & \text { kerabat } \\
\text { saya (Y1.4) } & \end{array}$ & 0 & 1 & 9 & 64 & 26 & 100 & 4.15 & Baik \\
\hline & Rata-rata & & & & & & & 3,80 & Baik \\
\hline
\end{tabular}


Menurut Ghozali (2013:114). Uji normalitas bertujuan untuk menguji apakah dalam model regresi variabel bebas dan variabel terikat mempunyai distribusi normal atau tidak.

Tabel 11.

Deskripsi Jawaban Responden Mengenai Penilaian Terhadap Variabel Loyalitas Pelanggan

\begin{tabular}{|c|c|c|c|c|c|c|c|c|c|}
\hline \multirow{2}{*}{ No. } & \multirow{2}{*}{$\begin{array}{c}\text { Pernyataan Tentang Loyalitas } \\
\text { Pelanggan (Y2) }\end{array}$} & \multicolumn{5}{|c|}{ Jawaban Responden } & \multirow{2}{*}{$\begin{array}{l}\text { Jml } \\
\text { Resp }\end{array}$} & \multirow{2}{*}{$\begin{array}{l}\text { Rata- } \\
\text { Rata }\end{array}$} & \multirow{2}{*}{ Ket } \\
\hline & & 1 & 2 & 3 & 4 & 5 & & & \\
\hline 1 & Saya berniat menjadikan produk & & & & & & & & \\
\hline & $\begin{array}{l}\text { Warunk Upnormal sebagai } \\
\text { prioritas utama (Y2.1) }\end{array}$ & 4 & 11 & 20 & 43 & 22 & 100 & 3,68 & Baik \\
\hline 2 & $\begin{array}{l}\text { Saya berniat untuk membeli } \\
\text { kembali produk Warunk Upnormal } \\
\text { (Y2.2) }\end{array}$ & 1 & 6 & 29 & 40 & 24 & 100 & 3,80 & Baik \\
\hline 3 & $\begin{array}{l}\text { Saya hanya akan membicarakan hal } \\
\text { positif tentang produk Warunk } \\
\text { Upnormal (Y2.3) }\end{array}$ & 1 & 1 & 28 & 46 & 24 & 100 & 3,91 & Baik \\
\hline & Rata-rata & & & & & & & 3,80 & Baik \\
\hline
\end{tabular}

Sumber: Data primer diolah, 2018

Tabel 12.

Hasil Uji Normalitas Struktur 1

\begin{tabular}{lc}
\hline & Unstandardized Residual \\
\hline $\mathrm{N}$ & 100 \\
Kolmogorov-Smirnov $Z$ & 0,079 \\
Asymp.Sig.(2-tailed) & 0,124 \\
Sumber $:$ Data diolah, 2018 &
\end{tabular}

Hasil uji Kolmogorov-Smirnov menunjukkan bahwa nilai Asymp.Sig. (2tailed) sebesar 0,124. Nilai ini lebih besar dari signifikan 0,05 sehinggan dapat disimpulakan bahwa data berdistribusi normal. Oleh karena itu asumsi normalitas pada regresi telah terpenuhi.

Tabel 13.

Hasil Uji Normalitas Struktur 2

\begin{tabular}{lc}
\hline & Unstandardized Residual \\
\hline $\mathrm{N}$ & 100 \\
Kolmogorov-Smirnov $\mathrm{Z}$ & 0,079 \\
Asymp.Sig. (2-tailed) & 0,131 \\
\hline Sumber $:$ Data diolah, 2018
\end{tabular}

Hasil uji Kolmogorov-Smirnov menunjukkan bahwa nilai Asymp.Sig.(2tailed) sebesar 0,131. Nilai ini lebih besar dari signifikan 0,05 sehingga dapat disimpulkan bahwa data berdistribusi normal. Oleh karena itu asumsi normalitas pada regresi telah terpenuhi.

Tabel 14.

Hasil Uji Multikolinearitas

\begin{tabular}{cccc}
\hline Persamaan Struktur & Variabel & Tolerance & VIF \\
\hline $\mathrm{Y}_{1}=\beta_{1} \mathrm{X}_{1}+\mathrm{e}_{1}$ & Inovasi Produk $\left(\mathrm{X}_{1}\right)$ & 1.000 & 1.000 \\
\hline
\end{tabular}




\begin{tabular}{lccc}
\hline $\mathrm{Y}_{2}=\beta_{3} \mathrm{X}_{1}+\beta_{5} \mathrm{Y}_{1}+\mathrm{e}_{2}$ & Inovasi Produk $\left(\mathrm{X}_{1}\right)$ & 0,528 & 1,892 \\
& Kepuasan Pelanggan $\left(\mathrm{Y}_{1}\right)$ & 0,528 & 1,892 \\
\hline
\end{tabular}

Sumber :Data diolah, 2018 (Lampiran 6)

Semua variabel independen yang digunakan memiliki nilai VIF yang dihasilkan kurang dari 10 dan nilai tolerance $>0,10$ sehingga dapat disimpulkan bahwa tidak terjadi korelasi ganda (multikoliniearitas) antar variabel independen. Oleh karena itu asumsi multikolinieritas telah terpenuhi.

Jika signifikan $\mathrm{t}$ dari hasil meregresi nilai absolute residual terhadap variabel bebas lebih besar dari 0,05 maka model regresi tidak mengandung heterokedastisitas.

\section{Tabel 15.}

\section{Hasil Uji Heterokedastisitas Struktur 1}

\begin{tabular}{lccccc}
\hline Model & \multicolumn{2}{c}{$\begin{array}{c}\text { Unstandardized } \\
\text { Coefficients }\end{array}$} & $\begin{array}{c}\text { Standardized } \\
\text { Coefficients }\end{array}$ & t & Sig \\
\cline { 2 - 6 } & $\mathrm{B}$ & Std. Error & Beta & & \\
\hline (Constant) &, 497 &, 127 & & 3,910 &, 000 \\
Inovasi Produk &,- 038 &, 032 &,- 120 & $-1,193$ &, 236 \\
$\left(\mathrm{X}_{1}\right)$ & & & & &
\end{tabular}

$\left(\mathrm{X}_{1}\right)$

Sumber:Data diolah, 2018

Tabel 16.

Hasil Uji Heterokedastisitas Struktur 2

\begin{tabular}{lccccc}
\hline Model & \multicolumn{2}{c}{$\begin{array}{c}\text { Unstandardized } \\
\text { Coefficients }\end{array}$} & $\begin{array}{c}\text { Standardized } \\
\text { Coefficients }\end{array}$ & t & Sig \\
\cline { 2 - 4 } & $\mathbf{B}$ & Std. Error & Beta & & \\
\hline (Constant) &, 114 &, 255 & &, 446 &, 656 \\
Inovasi &,- 057 &, 071 &,- 112 &,- 812 &, 419 \\
$\begin{array}{l}\text { Produk }\left(\mathrm{X}_{1}\right) \\
\text { Kepuasan }\end{array}$ &, 138 &, 090 &, 212 & 1,537 &, 127 \\
$\begin{array}{l}\text { Pelanggan } \\
\left(Y_{1}\right)\end{array}$ & & & & & \\
Sumber: Data diolah, 2018 & & & & & \\
\end{tabular}

Tabel 17.

Hasil Analisis Jalur Struktur 1

\begin{tabular}{lcccc}
\hline \multicolumn{1}{c}{ Variabel } & $\begin{array}{c}\text { Standardized } \\
\text { Coefficients }\end{array}$ & Std. Error & t hitung & Sig. Uji t \\
\hline (Constant) & & 0,227 & 7,574 & 0,000 \\
Inovasi produk $\left(\mathrm{X}_{1}\right)$ & 0,687 & 0,058 & 9,352 & 0,000 \\
R Square & 0,472 & & & \\
F statistic & 87,459 & & & \\
Signifikansi Uji F & 0,000 & & & \\
\hline
\end{tabular}

Sumber: Data diolah, 2018

Variabel bebas yang digunakan pada penelitian ini yaitu Inovasi Produk sebesar 0,236 nilai ini lebih besar dari 0,05 sehingga dapat disimpulkan bahwa tidak terjadi heterokedastisitas.

Untuk menguji variabel mediator memediasi hubungan antara variabel terikat dengan variabel bebas dapat dilakukan tahapan sebagai berikut:

a. Menghitung nilai 


$$
\begin{aligned}
& \mathrm{Sa}_{1} \mathrm{~b}=\sqrt{b^{2} s a_{1}^{2}+a_{1}^{2} s b^{2}+s a_{1}^{2} s b^{2}} \\
& \mathrm{Sa}_{1} \mathrm{~b}=\sqrt{0.572^{2} 0.058^{2}+0.538^{2} 0.136^{2}+0.058^{2} 0.136^{2}} \\
& \mathrm{Sa}_{1} \mathrm{~b}=0,080
\end{aligned}
$$

b. Menghitung nilai $\mathrm{a}_{1} \mathrm{~b}$

$\mathrm{a}_{1} \mathrm{~b}=0,538 \times 0,572$

$a_{1} b=0,307$

c. Menghitung nilai $Z_{1}$

$$
\begin{array}{r}
\mathrm{Z}_{1}=\frac{\frac{a_{1} b}{S a_{1} b}}{\mathrm{Z}_{1}=\frac{0,307}{0,080}} \\
\mathrm{Z}_{1}=3,837
\end{array}
$$

Tabel 18.

Hasil Analisis Jalur Struktur 2

\begin{tabular}{lcccc}
\hline \multicolumn{1}{c}{ Variabel } & $\begin{array}{c}\text { Standardized } \\
\text { Coefficients }\end{array}$ & Std. Error & t hitung & Sig. Uji t \\
\hline (Constant) & & 0,384 & 0,609 & 0,544 \\
Inovasi Produk $\left(\mathrm{X}_{1}\right)$ & 0,337 & 0,106 & 3,366 & 0,001 \\
Kepuasan (Y $\left.\mathrm{Y}_{1}\right)$ & 0,421 & 0,136 & 4,209 & 0,000 \\
R Square & 0,486 & & & \\
F statistic & 45,896 & & & \\
Signifikansi Uji F & 0,000 & & &
\end{tabular}

Variabel bebas yang digunakan pada penelitian ini yaitu Kepuasan Pelanggan $\left(\mathrm{Y}_{1}\right)$ sebesar 0,127, Inovasi Produk sebesar 0,419 nilai ini lebih besar dari 0,05 sehingga dapat disimpulkan bahwa tidak terjadi heterokedastisitas.

Nilai signifikansi Inovasi Produk $\left(\mathrm{X}_{1}\right)=0,001$ nilai ini lebih kecil dari 0,05 sehingga dapat disimpulkan bahwa variabel Inovasi Produk $\left(\mathrm{X}_{1}\right)$ berpengaruh signifikan terhadap variabel loyalitas pelanggan $\left(\mathrm{Y}_{2}\right)$ pelanggan Warunk Upnormal di Kota Denpasar.

Hasil tersebut mengindikasikan bahwa persepsi pelanggan terhadap Warunk Upnormal sudah baik, dikarenakan inovasi produk Warunk Upnormal bermacammacam sehingga pelanggan puas terhadap inovasi yang ditawarkan tersebut. Warunk Upnormal selalu mengutamakan kualitas makanan dan minuman yang disediakan untuk para pelanggan dan menyajikan menu makanan yang fresh. Inovasi produk yang di ukur berdasarkan indikator: penambahan varian produk, meningkatkan kualitas, dan menggunakan bahan baku baru terbukti mampu meningkatkan loyalitas pelanggan Warunk Upnormal di Kota Denpasar.

Hasil penelitian ini sesuai dengan rumusan hipotesis yang menyatakan bahwa inovasi produk berpengaruh positif dan signifikan terhadap loyalitas pelanggan di Kota Denpasar yang artinya semakin baik inovasi produk maka semakin baik loyalitas pelanggan. Hasil penelitian ini mendukung penelitian yang dilakukan oleh Roring dkk. (2014) menyatakan bahwa inovasi produk berpengaruh positif dan 
signifikan terhadap loyalitas pelanggan. Sehingga apabila inovasi desain dikembangkan maka pelanggan akan merasa puas dan loyal (Caesar, 2017).

Nilai signifikan inovasi produk $\left(\mathrm{X}_{1}\right)=0,000$ nilai ini lebih kecil dari 0,05 sehingga dapat disimpulkan bahwa variabel inovasi produk $\left(\mathrm{X}_{1}\right)$ berpengaruh positif dan signifikan terhadap kepuasan pelanggan $\left(\mathrm{Y}_{1}\right)$ pelanggan Warunk Upnormal di Kota Denpasar. Hasil tersebut mengindikasikan bahwa inovasi produk yang baik, inovasi produk yang fresh dan beragam akan membuat pelanggan merasa puas dengan apa yang disajikan Warunk Upnormal. Inovasi produk yang di ukur berdasarkan indikator: penambahan varian produk, meningkatkan kualitas, dan menggunakan bahan baku baru terbukti mampu meningkatkan kepuasan pelanggan Warunk Upnormal di Kota Denpasar.

Hasil penelitian ini sesuai dengan rumusan hipotesis yang menyatakan bahwa pengaruh inovasi produk berpengaruh positif dan signifikan terhadap kepuasan pelanggan. Hal tersebut didukung oleh Sujadi \& Wahyono (2015) dan Agung (2016) yang menyebutkan semakin baik inovasi produk yang ditawarkan maka semakin tinggi tingkat ketertarikan pelanggan untuk membeli sebuah produk tersebut.

Nilai signifikansi kepuasan pelanggan $\left(\mathrm{Y}_{1}\right)=0,000$ nilai ini lebih kecil dari 0,05 sehingga dapat disimpulkan bahwa variabel kepuasan pelanggan ( $\left.\mathrm{Y}_{1}\right)$ memiliki pengaruh signifikansi terhadap variabel loyalitas pelanggan $\left(\mathrm{Y}_{2}\right)$ Warunk Upnormal di Kota Denpasar. Hasil tersebut mengindikasikan bahwa pelanggan yang merasa harapannya terpenuhi dengan rasa senang dan puas terhadap warunk upnormal maka bisa loyal terhadap warunk upnormal dan bisa merekomendasikan Warunk Upnormal kepada kerabat terdekat. Kepuasan pelanggan yang diukur berdasarkan indikator: terpenuhinya harapan, rasa senang dan puas, kesediaan merekomendasikan, dan kepuasan secara menyeluruh terbukti mampu meningkatkan loyalitas pelanggan Warunk Upnormal di Kota Denpasar.

Hasil penelitian ini sesuai dengan rumusan hipotesis yang menyatakan bahwa pengaruh kepuasan pelanggan berpengaruh positif dan signifikan terhadap loyalitas pelanggan Warunk Upnormal di Kota Denpasar. Hasil penelitian ini mendukung penelitian (Hidayat, 2014) yang menyatakan kepuasan pelanggan berpengaruh positif dan signifikan terhadap loyalitas pelanggan. Sehingga semakin tinggi rasa kepuasan pelanggan maka semakin tinggi tingkat loyalitas pelanggan (Purwa, 2017).

Hasil perhitungan didapatkan perhitungan nilai $\mathrm{z}$ hitung sebesar $3,837>\mathrm{z}$ tabel sebesar 1,96, maka hipotesis $\mathrm{H}_{4}$ diterima yang artinya kepuasan pelanggan mampu memediasi secara signifikan pengaruh inovasi produk terhadap loyalitas pelanggan. Hasil ini diketahui bahwa pengaruh langsung yang diberikan inovasi produk (X1) terhadap loyalitas pelanggan sebesar 0,337. Sedangkan pengaruh tidak langsung Inovasi Produk $(\mathrm{X})$ melalui Kepuasan Pelanggan $\left(\mathrm{Y}_{1}\right)$ adalah perkalian antara nilai beta Inovasi Produk $(\mathrm{X})$ terhadap Kepuasan Pelanggan $\left(\mathrm{Y}_{1}\right)$ dengan nilai beta Kepuasan Pelanggan ( $\left.\mathrm{Y}_{1}\right)$ terhadap Loyalitas Pelanggan (Y2) yaitu : $0,687 \times 0,421=0,289$. Maka pengaruh total yang diberikan oleh Inovasi Produk (X) terhadap Loyalitas Pelanggan $\left(\mathrm{Y}_{2}\right)$ adalah pengaruh langsung ditambah pengaruh tidak langsung yaitu : $0,337+0,289=0,626$. 
Berdasarkan nilai perhitungan dapat diketahui bahwa nilai pengaruh langsung sebesar 0,337 dan pengaruh tidak langsung sebesar 0,289 yang berarti bahwa nilai pengaruh langsung lebih besar dari nilai pengaruh tidak langsung. Berdasarkan hasil tabel diatas dijelaskan bahwa inovasi produk berpengaruh secara nyata terhadap loyalitas pelanggan, inovasi produk berpengaruh secara nyata terhadap kepuasan pelanggan, dan kepuasan pelanggan berpengaruh secara nyata terhadap loyalitas pelanggan maka dalam hal ini disebut mediasi parsial. Hasil penelitian ini sesuai dengan rumusan hipotesis yang menyatakan bahwa kepuasan pelanggan memediasi pengaruh inovasi produk berpengaruh positif dan signifikan terhadap loyalitas pelanggan (Agung, 2016).

Implikasi dari hasil penelitian ini terdapat dua hal yaitu, implikasi teoritis dan implikasi praktis. Implikasi teoritis berhubungan dengan kontribusinya bagi perkembangan teori-teori mengenai variabel inovasi produk, kepuasan pelanggan dan loyalitas pelanggan. Sedangkan implikasi praktis berkaitan dengan kontribusi penelitian terhadap peningkatan nilai merek bagi perusahaan-perusahaan yang bergerak dalam bisnis warung, khususnya Warunk Upnormal (1) Berdasarkan penelitian yang sudah dilakukan sehingga dapat diketahui bahwa secara teoritis, Penelitian ini dapat memberikan kontribusi empiris tentang hubungan antara variabel inovasi produk (X), kepuasan pelanggan (Y1) dan loyalitas pelanggan (Y2) bagi pengembangan ilmu pemasaran. (2) Hasil penelitian ini diharapkan dapat digunakan bagi manajemen Warunk Upnormal dalam merancang strategi pemasaran berdasarkan inovasi produk guna meningkatkan kepuasan pelanggan dan loyalitas pelanggan yang positif terhadap produk Warunk Upnormal. Strategi yang dapat dilakukan oleh perusahaan yaitu dengan meningkatkan inovasi produk dan terus melakukan inovasi produk misalnya memadukan masakan nusantara dengan modern, contohnya mie tektek yang diberi varian topping keju diatasnya. Sehingga Warunk Upnormal menjadi populer agar pelanggan menjadi puas dan mampu menjadi loyal terhadap Warunk Upnormal.

Patut disadari bahwa terdapat beberapa keterbatasan dari penelitian ini yang diantaranya (1) Ruang lingkup penelitian yang terbatas pada wilayah Kota Denpasar, sehingga hasil penelitian ini tidak dapat digeneralisasi untuk pelanggan di wilayah yang lebih luas. (2) Mengingat penelitian ini dilakukan dalam jangka waktu tertentu (cross section) sedangkan lingkungan bisa mengalami perubahan seperti daya beli pelanggan, maka penelitian ini penting dilakukan di masa yang akan datang.

\section{SIMPULAN}

Berdasarkan hasil analisis dan pembahasan mengenai bagaimana peran kepuasan pelanggan dalam memediasi pengaruh inovasi produk terhadap loyalitas pelanggan (studi pada pelanggan Warunk Upnormal di Kota Denpasar, Bali) maka dapat ditarik kesimpulan bahwa inovasi produk memiliki pengaruh positif dan signifikan terhadap loyalitas pelanggan dan kepuasan pelanggan, dan kepuasan pelanggan memiliki pengaruh positif dan signifikan terhadap loyalitas pelanggan dan kepuasan pelanggan secara signifikan berperan memediasi pengaruh inovasi produk terhadap loyalitas pelanggan. 
Berdasarkan hasil analisis penelitian, pembahasan dan kesimpulan terdapat beberapa saran yang dapat dipergunakan sebagai bahan pertimbangan dalam menentukan kebijakan terkait mempertahankan dan meningkatkan loyalitas warunk upnormal dimasa mendatang seperti pihak manajemen Warunk Upnormal sebaiknya selalu mengevaluasi inovasi-inovasi yang sudah pernah dilakukan dan terus melakukan inovasi-inovasi baru yang belum dilakukan oleh warung lainnya, pihak manajemen warunk upnormal sebaiknya selalu mengevaluasi dan memperhatikan pengguna dalam memaksimalkan kepuasan pelanggan tersebut, dan pihak manajemen Warunk Upnormal sebaiknya selalu mengevaluasi dan memperhatikan pengguna dalam memaksimalkan loyalitas pelanggan tersebut.

\section{REFERENSI}

Agung, I. M. (2016). Pengaruh Inovasi Produk terhadap Loyalitas Pelanggan dengan Kepuasan Konsumen sebagai Variabel Intervening (Studi pada Kafé Fruit Caffe Refresho di Tulungagung). Jurnal Ilmu Manajemen Universitas Negeri Surabaya, 4, 129-138.

Ali, H. (2013). Marketing dan Kasus-Kasus Pilihan. In Yogyakarta. CAPS (Center For Academic Publishing Service).

Alifuddin, M., \& Razak, M. (2015). Kewirausahaan Strategi Membangun Kerajaan Bisnis. In Jakarta :Magna Script Publishing.

Atalay, M., Sarvan, F., \& Anafarta, N. (2013). The Relationship Between Innovation And Firm Perfomance: An Empirical Evidence From Turkish Automotive Supplier Industry. Social and Behavioral Science, 226-235. https://doi.org/10.1016/j.sbspro.2013.04.026

Bayraktar, E., Tatoglu, E., Turkyilmaz, A., Delen, D., \& Zaim, S. (2012). Measuring The Effieciency Of Customer Satisfaction And Loyalty For Mobile Phone Brands With DEA. International Journal of Expert Systems with Applications, 39(1), 99-106. https://doi.org/10.1016/j.eswa.2011.06.041

Caesar, M. S. D. P., \& Ekawati, N. W. (2017). Pengaruh Inovasi Produk,Harga,Citra Merek dan Kualitas Pelayanan terhadap Loyalitas Pelanngan Sepeda Motor Vespa. E-Jurnal Manajemen Unud, 6(3), 16741700.

Cahyo, R. J., \& Harjanti, D. (2013). Analisis Inovasi Produk Pada Sektor Usaha Formal Dan Informal Di Jawa Timur. AGORA, l(3).

Chyntia, V. D., \& Tawas, H. N. (2014). Pengaruh Orientasi Kewirausahaan, Inovasi Produk, dan Keunggulan Bersaing terhadap Kinerja Pemasaran Usaha Nasi Kuning di Kota Manado. Jurnal Riset Ekonomi, Manajemen, Bisnis Dan Akuntansi., 2(3), 1214-1224.

Fatkhurrohman, D. M. (2011). The Effect of Innovation Factors to Customer Loyalty by Structural Equation Model. Jurnal of Economics and Management 
Engineering, 5(4), 370-374.

Ghozali, I. (2013). Aplikasi Analisis Multivariate dengan Program SPSS Edisi keempat. In Penerbit Universitas Diponegoro (pp. 82-88).

Hafeez, S., \& Muhammad, B. (2012). The Impact of Service Quality, Customer Satisfaction and Loyalty Programs on Customer's Loyalty: Evidence Banking Sector of Pakistan. International Journal of Business and Social Science, 3(16), 200-209.

Henriawan, D. (2015). Pengaruh Kualitas Pelayanan dan Kepuasan Pelanggan Terhadap Loyalitas Pelanggan (Studi Kasus pada Toko Cabang Mufin Wilayah Bandung Timur). Universitas Sebelas April, 71-82.

Hidayat, D. R. (2014). Analisis Pengaruh Kualitas Layanan, Harga, Kepercayaan, Citra Perusahaan, dan Kepuasan Pelanggan Terhadap Loyalitas Pelanggan (Studi Pada Pelanggan Telkom Speedy di Palangka Raya). Jurnal Wawasan Manajemen, 2(3).

Jian, K., Xin, Z., \& Zhao-Hong, Z. (2009). The relationship of customer complaints, satisfaction and loyalty: Evidence from China's mobile phone industry. ChinaUSA Business Review, 8(12), 22-36.

Kotler, P., \& Keller, K. L. (2016). Marketing Managemen, 15th Edition,. In Pearson Education, Inc. https://doi.org/10.7441/joc.2016.02.08

Lee, H. S. (2013). Major Moderators Influencing the Relationships of Service Quality, Customer Satisfaction and Customer Loyalty. Asian Social Science, 9(2), 1-11. https://doi.org/10.5539/ass.v9n2p1

Masda, P. . (2012). Pengaruh Inovasi Produk dan Harga terhadap Keputusan Pembelian Galamai di Kota Payakumbuh. E-Journal Fakultas Ekonomi, Universitas Negeri Padang, 2(1).

McDaniel, B. A. (2002). Entrepreneurship and Innovation:An Economic Approach. M.E. In New York: Sharpe,Inc,

Nugroho, A. W., \& Sudaryanto, B. (2013). Pengaruh Kinerja Layanan,Kepercayaan Dan KepuasanTerhadap Loyalitas KonsumenDalam Menggunakan JasaPengiriman Barang,. Diponogoro Journal Of Management., 2, 1-9.

Pishgar, F., Dezhkam, S., Ghanbarpoor, F., Shabani, N., \& Ashoori, M. (2013). The Impact of Product Innovation on Customer Satisfaction and Customer Loyalty. Kuwait Chapter of Arabian Journal of Business and Management Review., 2(5), 135-142.

Purwa, A. M., \& Wulandari, K. M. (2017). Peran Kepuasan Pelanggan dalam Memediasi Pengaruh Kualitas Pelayanan terhadap Loyalitas Pelanggan. EJurnal Manajemen Unud., 6(9), 5061-5087.

Roring, B. C., Mekel, P. A., \& Soegoto, A. . (2014). Pencitraan Merk, Penetapan Harga dan Inovasi Produk Pengaruhnya terhadap Loyalitas Konsumen dalam 
Membeli Mobil Toyota Avanza di Kota Manado. Jurnal EMBA :Jurnal Riset Ekonomi, Manajemen, Bisnis Dan Akuntansi, 2(3), 1225-1236.

Santoso, I. (2016). Peran Kualitas Produk dan Layanan, Harga dan Atmosfer Rumah Makan Cepat Saji terhadap Keputusan Pembelian dan Kepuasan Konsumen. Jurnal Universitas Brawijaya, Malang, 15(1).

Sawitri, N. P., Kerti, N. N. Y., \& Jawas, A. (2013). Pengaruh Kualitas Pelayanan terhadap Kepuasan dan Loyalitas Pelanggan Tegal Sari Accommodation di Ubud,. Jurnal Manajemen, Strategi Bisnis, Dan Kewirausahaan., 7(1), 40-47.

Shanin, A., Abandi, A. A., \& Javadi, M. H. M. (2011). Analyzing The Relationship Between Customer Satisfaction and Loyalty In The Software Industry - With a Case Study In Isfahan System Group. International Journal of Bussiness and Social Science, 2(23), 129-136.

Singh, A. P., \& Thakur, S. (2012). Impact Of Service Quality On Customer Satisfaction and Loyalty: In The Context Of Retail Outlets In DB City Shopping Mall Bhopal. Journal of Management Research And Review, 2(2), 334-344.

Sugiyono. (2014). Metode Penelitian Bisnis (Pendekatan Kuantitatif, Kualitatif dan R\&D). In Bandung: Alfabeta.

Sujadi, T. P., \& Wahyono. (2015). Pengaruh Inovasi dan Kualitas Produk terhadap Loyalitas Konsumen The Botol Sosro dengan Kepuasan Sebagai Variabel Intervening. Management Analysis Journal, 4(4), 326-332.

Sukarmen, P., Sularso, A., \& Wulandari, D. (2013). Analisis Pengaruh Inovasi Produk Terhadap Kepuasan Konsumen dengan Keunggulan Bersaing sebagai Variabel Intervening pada Produk Gula Pasir Sebelas (GUPALAS) Pabrik Gula Semboro PTP Nusantara XI (Persero), XII(1), 64-79.

Sumertana, I. W. (2016). Pengaruh Kualitas Pelayanan terhadap Loyalitas Pelanggan dengan Kepuasan Pelanggan sebagai Variabel Intervening pada Water Park Seririt Singaraja tahun 2014-2015. Jurnal Program Studi Pendidikan Ekonomi., 7(2).

Tahir, N., Irum, A., \& Khaliq, U. R. C. (2012). The Impact of Innovation on Customer Satisfaction and Brand loyalty: A Study of the Students of Faisalabad. Http://Mpra.Ub.Uni-Muenchen.de/53197/, (53197).

Te, Y., Li, M. L., \& Chi, C. H. (2013). An Empirical Study of Corporate Brand Image, Customer Perceived Value and Satisfaction on Loyalty in Shoe Industry. Journal of Economics and Behavioral Studies, 5(7), 469-483.

www.bps.go.id.

www.warunkupnormal.com. 